\title{
Review Article: Why Environmental Impact Assessment Failed in the Floriculture Industry in Ethiopia
}

\author{
Sara Birkie \\ Ethiopian Institute of Agricultural Research, P.O.Box 2003, Addis Ababa, Ethiopia
}

\begin{abstract}
Floriculture as an industry in Ethiopia is a huge industry that counts a decade. The sector began in 1997 with only two flower farms, however, today has grown more than 80 active flower farms. The industry has grown because of several favorable factors like the vicinity of the country to the global market, encouraging investment law, very cheap labor power, moreover suitable environmental resources like soil, groundwater, etc. Though it is one of the leading industry to make the country get forging currency, several environmental, animal and human health concern increases through time because of the industry uses lager amount of hazardous chemical for the pesticides purpose and growth regulator, which ends up finally with few treatment or not at all any treatments directly damp in to the environment and lead to adverse environmental impacts. This paper reviewed about gaps in the regulatory framework and the problem of not having effective regulation in such kind of industry.
\end{abstract}

Keywords: Floriculture, Environmental policy, Environmental impact assessment

DOI: $10.7176 / \mathrm{JEES} / 9-9-02$

Publication date:September $30^{\text {th }} 2019$

\section{Introduction}

Floriculture which is a branch of horticulture that is focusing on the cultivation of flowers and ornamental plants is relatively one of the youngest agro-industry in Ethiopia (Mulugeta, 2009). At the beginning, in 1997 there were only two flower farms and with rapid expansion, more than 80 farms were reported to exist in 2010. This was due to a number different factors, like favorable agro ecology, cheap labor, conducive investment law and incentives and bank loans that attract investment in the sector. Ethiopia stands as the second and sixth largest flower producer in Africa and in the world respectively (EHPEA, 2007and UN Special Envoy, 2007). Based on Ethiopian investment agency the sector created job opportunity for more than 100,000 Ethiopians and it is among the top five industry earning foreign currency in the country. However, the huge economic benefits in relation to job creation and hard currency earning under masked the environmental and health hazard that the sector imposes through water and soil pollutions due to the application of fertilizers, use of pesticides and depletion of the water resource. (Tamrat, 2011; Jansen \& Harmsen, 2011). Even though the environmental impact of the sector is believed to be exaggerated by some government officials, Others accepted the presence of the problem but, they believed that environmental problems due to development activities are not new in any part of the world and something will be sacrificed to get another bigger one (Mulugeta, 2009). However, different studies showed that the country is drowning into a problem that will cost a lot now and in the future (Hengsdijk \& Jansen, 2006; Mulugeta, 2009; Tamrat, 2011; Jansen \& Harmsen, 2011). This paper focused on the environmental problems related to the floriculture industry and the environmental policies and regulations implementation in practice.

\section{Environmental Impact of Floriculture}

Due to the rapid growth of the floriculture sector in the country worries about its adverse environmental impact has been an ever-increasing agenda the major impacts of the sector are summarized as follow.

\section{Impact on Water Bodies}

Application of chemicals like fertilizer and pesticides that could leak through the soil to underground water, rivers, and streams can cause water pollution. For instance, through the process of eutrophication applied fertilizers can cause the growth of algae on the surface of the water that hinders the aquatic vegetation to sunlight, exposing their survival and other aquatic lives at risk. (Mulugeta, 2009). Similarly, pesticides contaminated water bodies can be harmful to the fish and other marine or freshwater animals (Mulugeta, 2009). Moreover, Solid wastes and toxic chemicals that are disposed from the sector can develop water born disease (Abiy, 2011)

\section{Impact on Soil}

Continued use of chemical fertilizers may destroy different useful microorganism which responsible for keeping the soil at its natural integrity. Mostly chemical fertilizers resulted in a more acidic soil which creates an unfavorable condition for microorganisms and it will reduce the bioavailability of the most nutrient. In addition to that different wastes of the sector that are dumped on and into the soil will change the soils physical and chemical properties resulting unproductive soil (USEPA, 1996). 


\section{Impact on Air}

The use of intensive fertilizer ammonia could escape into the air where it will react with the water in the air forming ammonia oxide and likewise, the most pesticide is volatile and pollutes the air. Almost 80 to $90 \%$ of applied pesticide will volatilize within few days of application (USGS, 2009). Chemicals like Methyl bromide that are believed to cause ozone depletion are being practiced as a soil fumigant in floriculture sector (Abiy, 2011).

\section{Health impact}

Contamination of groundwater by nitrates and use of the water have been reported to cause a disease called Methemoglobinemia (blue-baby syndrome). Livestock grazing in a field with high contamination of chemical fertilizers are also exposed to different diseases. Workers that are engaged in the sector are also at high risk of being affected by the chemicals that are used. According to (Fatuma, 2008) due to a proximity of the greenhouse to the main road and houses, people were complaining about irritation and bad/pungent smell that is coming out of the farm.

\section{Impact on Land Cover Change}

Due to the expansion of floriculture land use change, forest cover and farm lands to floriculture farms have been seen in different part of the country. Hence, this change resulted in a shortage of agricultural products, fuel, and construction woods in the locality (Fatuma, 2008).

\section{Waste Disposal}

Waste can be in the form of solid or liquid and different kind of them which could be, hazardous or not are disposed of floriculture industries. Wastes like chemical containers, plant residue, plastics, container washing waters, obsolete chemicals, preservatives, burned fuels etc. Are becoming major concern related to the sector. Because their improper management would result in a significant environmental as well as social problems as described in the above sections. However, according to Abiy (2011), Ethiopian flower farms have been censured for not implementing appropriate waste management systems.

\section{Environmental Policy and Laws of Ethiopia}

The Environmental Policy of Ethiopia (EPE) contain various policy directions to conserve and protect the environmental resource for sustainable use (EPE, 1997). Generally, the basic principle of the policy is to make a wise decision between the short-term economic advantages of any development projects that may cause a longterm environmental problem which could result in expensive environmental rehabilitation. Hence, the EPE require the undertaking of full environmental, social and economic impact assessment of all development plans. Moreover, Ethiopian water Sector Policy and the Ethiopian water Sector Strategy require the protection environment in any waste related development plans where Environmental Impact Assessment (EIA) is compulsory. In addition to that even though there is a gap on the responsibility of formulating different standards on water use quality, quantity with their limit and range of acceptable level, waste discharge, etc. It is considered for the establishment. Wastewater treatment has been given a due emphasis by EPE when it is safe and cheap. Likewise, EPE advocates the use of organic fertilizer and demanded waste management through the development of guidelines and strategies even though there is a concern on their formulation in the past decade (Mulugeta 2009).

Environmental Impact Assessment Proclamation that came into practice since 2002, has the power to control the adverse impact that floriculture industry may impose on the environment. The goal of an EIA is to promote sustainable development and a better quality of life by solving the negative aspects and enhancing the positive impact of a project (Damtie \& Bayou, 2008). EIA is a legal procedure that necessitates development plans and new industry to be evaluated for environmental, political, socioeconomic and cultural impacts before going to into an action (Environmental Policy of Ethiopia, 1990; Damtie \& Bayou, 2008). However, despite the proclamation set $\$ 2,754$ to $\$ 5,509$ punishment for the project started before the EIA is complete, it is usually poorly enforced ((Damtie \& Bayou, 2008, Assefa, 2008). Therefore, coming to the floriculture industry very few EIA has been used to evaluate the environmental safety of the flower industries so far. Surprisingly, the biggest flower industry Sher flower farm with about 500-hectare area have not done EIA so far. According to Mulugeta (2013), until 2009 only around 20 floriculture industries have done EIA

\section{Why Environmental Impact Assessment failed in the floriculture industry?}

As indicated in the flowchart (figure 1) segmented EIA processes that are watered down to implementing sectors is majorly responsible for the failure of EIA on the floriculture industries in Ethiopia. Solomon (2009) reported that the investment proclamations that came after environmental proclamations are superior in the hierarchy, have got a more political will and are ultimately devaluing the importance of EIA and sustainable development. For instance, the Investment agency in the view of one window shopping' service to accelerate the investment permits, gave permission before EIA was done. Hence, this poor coordination between the sectors resulted in the 
transferring of the EIA review process to different sectoral bodies, like the Ministry of Agriculture, the Ministry of water, the ministry of health, the Investment Agency etc. Due to that, the floriculture industry's EIA is expected to be reviewed by the ministry of agriculture which is the implementing agency of the project rather than the regulatory body which lack professionals on the subject matter. EPA do EIA in specific conditions when the international fund seeks for the development project and mostly it has monitoring role of the sectors. Moreover, EPA has its body at the regional level called REA which has the same authority with the EPA in the region. sometimes regional investment office grants permission and in this case, REA is responsible for EIA and due to lack of expertise at the regional level and segmentation of the process the EIA process is negligible. In the other hand, EPA requires a consulting firm to conduct the EIA process which should be composed of different disciples, known to be neutral, having curriculum vitae and registration license. However, there is no consulting agency approved by the EPA. In other hands, Ethiopian Horticulture Producers and Exporters Association (EHPEA) established by the farms have developed the code of practice to penetrate the international market and even though nothing mentioned about EIA in the practice it has positive in reducing the environmental impact the sector. Generally, laws and policies that are formulated to protect the environment are being suppressed by other sector's laws with different interest, like investment law and inappropriate measures taken like the case of delegating the EIA process to unorganized and no regulatory bodies. Therefore, even though the flower industry is growing at higher rate in Ethiopia the number of farmers that have done EIA are very negligible.

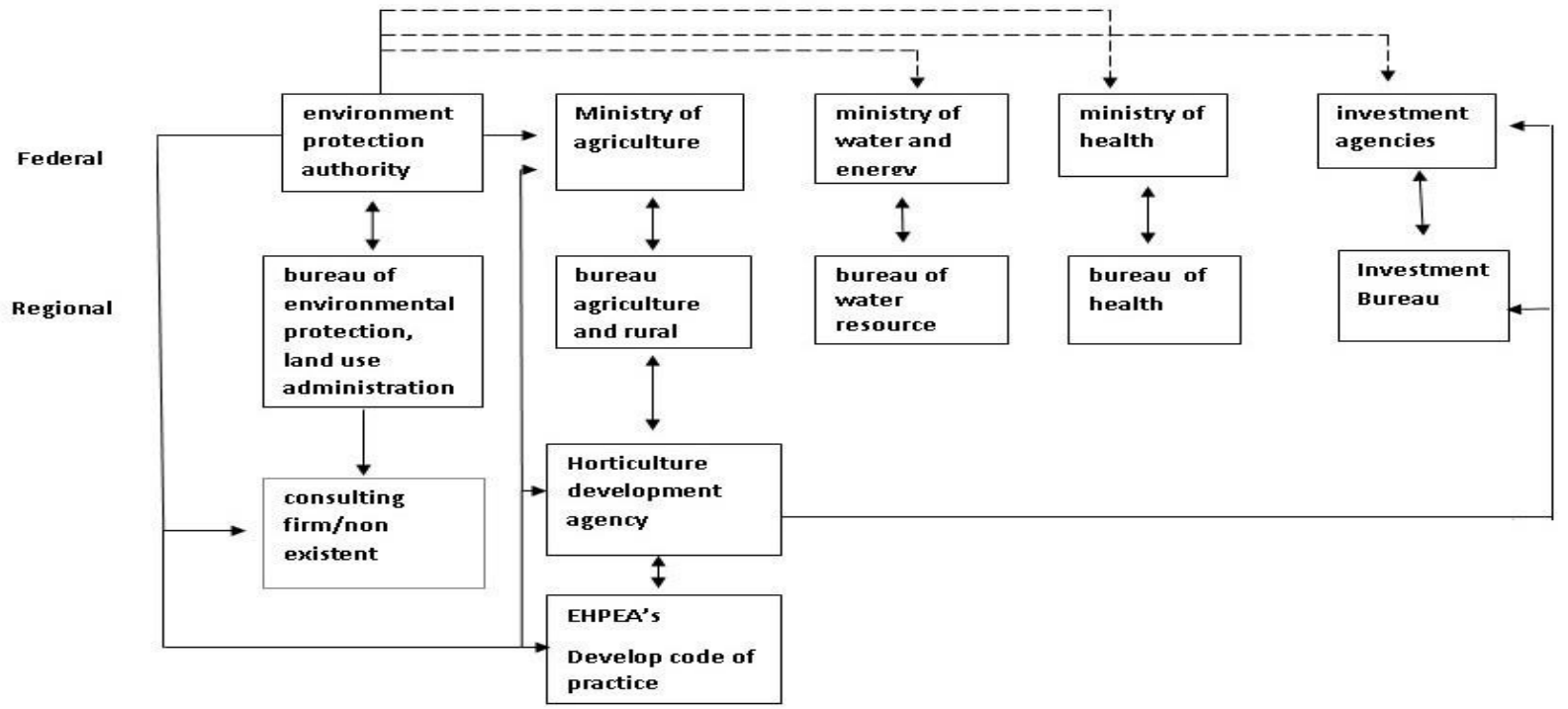

Figure -1 Segmentation of EIA process to floriculture industries across different implementing bodies and regulatory body (EPA). Horticulture development agency and EHPEA have indirect impact on the process

EPA will do EIA when International funding bodies demand it

\section{Reference}

- Abiy Tamirat (2011). Toxication in Bits Flower Industry Threatens Right to Water in Ethiopia CutFlower Production Practices, the Sector`s Socio-Economic Contribution and Environmental Standards. Addis Ababa, Ethiopia.

- $\quad$ Assefa, T. (Ed.). (2008). Digest of Ethiopia's National Policies, Strategies \& Programs. Addis Ababa: Forum for Social Studies.

- Damtie, M., \& Bayou, M. (2008). Overview of Environmental Impact Assessment in Ethiopia: Gaps and Challenges. (N. Benequista, Ed.). Addis Ababa: MELCA Mahiber.

- $\quad$ EHPEA. (2007). Ethiopian Horticulture Producer Exporters Association: Code of Practice for Sustainable Flower Production. EHPEA, 1(June).

- $\quad$ Environmental Policy of Ethiopia. (1997). Environmental Policy of Ethiopia, 1-29.

- $\quad$ Fatuma A. (2008). Social and Environmental Implication of Floriculture: a stakeholder perception Analysis at Holeta Area, Wolmera District, Oromia Region. Addis Ababa University. School of Graduate Studies. Environmental Science Program. Addis Ababa, Ethiopia.

- Mulugeta Getu, M. (2009). Ethiopian Floriculture and its impact on the environment: Regulation, 
Supervision, and Compliance.

- Hengsdijk, H., \& Jansen, H. (2006). Agricultural Development in the Central Ethiopian Rift Valley: A Deskstudy on Water-related Issues and Knowledge to Support a Policy Dialogue. Plant Research International B.V., Wageningen, (January), 1-25.

- $\quad$ Jansen, H. C., \& Harmsen, J. (2011). Pesticide Monitoring in the Central Rift Valley 2009 - 2010: Ecosystems for Water in Ethiopia. Alterra Wageningen UR, 44.

- Tamrat, A. (2011). Toxication in Bits: Flower Industry Threatens Right to Water in Ethiopia, Cut-Flower Production Practices, the Sector's Socio-Economic Contribution and Environmental Standards. Fian Germany.

- UN Special, Ethiopian Millennium - Coming up Roses. (2007). After Coffee - Ethiopia’s Other Export, p (40 - 41.)

- United States Environmental Protection Agency (USEPA) (1996). Cut-Rose: Request for Exception to Worker Protection Standard's Prohibition of Early Entry in to Pesticide - Treated Areas to Harvest Roses by Hand Cutting. EPA Document Volume 61, Number 211.

- USGS. Pesticides in the atmosphere: current understanding of distribution and major influences. Fact Sheet FS-152-1995. http://water.wr.usgs.gov/pnsp/atmos/ last visited on May 27, 2009 